AperTO - Archivio Istituzionale Open Access dell'Università di Torino

\title{
Evidence of Haldol (haloperidol) long-term intoxication
}

\section{This is the author's manuscript}

Original Citation:

Availability:

This version is available http://hdl.handle.net/2318/90913

since 2015-12-29T11:49:19Z

Published version:

DOI:10.1016/j.forsciint.2011.01.038

Terms of use:

Open Access

Anyone can freely access the full text of works made available as "Open Access". Works made available under a Creative Commons license can be used according to the terms and conditions of said license. Use of all other works requires consent of the right holder (author or publisher) if not exempted from copyright protection by the applicable law. 


\section{(c) \\ UNIVERSITÀ DEGLI STUDI DI TORINO}

This is an author version of the contribution published on:

Forensic Science International, 215, 1-3, 2012, DOI: 10.1016/j.forsciint.2011.01.038

E. Gerace, A. Salomone, S. Pellegrino, M. Vincenti

volume 215, Elsevier, 2012, 121-123

The definitive version is available at:

http://www.sciencedirect.com/science/article/pii/S0379073811000533

This Accepted Author Manuscript (AAM) is copyrighted and published by Elsevier. It is posted here by agreement between Elsevier and the University of Turin. Changes resulting from the publishing process - such as editing, corrections, structural formatting, and other quality control mechanisms may not be reflected in this version of the text.

You may download, copy and otherwise use the AAM for non-commercial purposes provided that your license is limited by the following restrictions:

(1) You may use this AAM for non-commercial purposes only under the terms of the CC-BY-NC-ND license.

(2) The integrity of the work and identification of the author, copyright owner, and publisher must be preserved in any copy.

(3) You must attribute this AAM in the following format: Creative Commons BY-NC-ND license (http://creativecommons.org/licenses/by-nc-nd/4.0/deed.en), [+ Digital Object Identifier link to the published journal article on Elsevier's ScienceDirect ${ }^{\circledR}$ platform] 


\section{Abstract}

A case of intoxication by haloperidol is reported. Haloperidol is a butyrophenone derivative commonly used in many hospital units as an antipsychotic agent. Adverse reactions due to haloperidol intoxication include drowsiness, blurred vision, extrapyramidal effects, tardive dyskinesia, tachycardia, hypotension and muscular rigidity. In August 2008, a 49 year-old female nurse started feeling various symptoms such as muscular rigidity, drowsiness and buccal dyskinesia. After 3 months, she was hospitalized for the worsening of these symptoms. Four months later, she showed once more the same symptoms. Two open water bottles from which the nurse used to drink in the hospital were confiscated and analyzed. Moreover, the nurse was asked to give a sample of her hair for executing the inherent toxicological analyses. Haloperidol was found in both bottles 1 and 2 at a concentration of $31.5 \mu \mathrm{g} / \mathrm{mL}$ and $43.6 \mu \mathrm{g} / \mathrm{mL}$, respectively. Based on segmental hair analysis, it was deduced that the nurse consumed haloperidol in the approximate period from August 2008 to March 2009. The higher levels of haloperidol in hair were found in accordance with the periods of most severe appearance of symptoms, requiring the hospitalization of the nurse. The analysis of preservatives and excipients led us to conclude that the pharmaceutical drug was probably added to the water bottles as "Haldol $2 \mathrm{mg} / \mathrm{mL}$ oral solution".

\section{Keywords}

- Haloperidol;

- Hair analysis;

- GC/MS;

- Forensic toxicology;

- Intoxication 


\section{Introduction}

Haloperidol is a butyrophenone derivative synthesized in 1958 and first marketed in the United States in 1967. It is an effective antipsychotic agent commonly used in the treatment of schizophrenia and, more acutely, in the treatment of acute psychotic states and delirium [1]. The first molecules used as antipsychotic drugs, such as phenothiazines (promethazine, chlorpromazine) and butyrophenones (haloperidol) proved to cause a large number of side effects, but intoxications from their abuse were seldom reported as life threatening [2]. Adverse reactions to haloperidol intoxication include drowsiness, blurred vision, extrapyramidal effects, tardive dyskinesia, tachycardia, hypotension and muscular rigidity [1], $\underline{\text { [3] }}$ and [4]. Haloperidol is available in Italy mainly under the trade names of Serenase and Haldol. It is produced at different concentrations as tablets, oral solution, and injectable solution. This report describes a case of chronic intoxication involving haloperidol.

\section{Case report}

In August 2008, a 49 year-old female nurse started feeling various symptoms including muscular rigidity, drowsiness and buccal dyskinesia. Three months later, she was hospitalized for the aggravation of these symptoms. In March 2009, she showed once more the same symptoms. As she used to drink water from her own bottle stored in a shared refrigerator in the hospital, she claimed that some drugs could have been added to her water by someone working in the same unit. Some of her colleagues corroborated her suspects suggesting that the content of the bottle released an unusual smell. Therefore, she reported the episode to the justice.

All the staff working in the unit had similar bottles stored in the same refrigerator and each bottle's owner was identified by his/her initials written on the bottle. Two open water bottles (residual volumes in bottles 1 and 2 were $280 \mathrm{~mL}$ and $135 \mathrm{~mL}$, respectively) owned by the nurse and recently stored were confiscated and analyzed. In order to evaluate more directly the nurse exposition to drug of abuse or other xenobiotics, she was asked to give a sample of her hair for executing the inherent toxicological analyses.

\section{Materials and methods}

\subsection{Specimen}

To execute a segmental analysis, proximal and distal portions of hair were identified. Assuming that hair growth rate generally ranges from 1.0 to $1.3 \mathrm{~cm} / \mathrm{month}[5]$, a relationship between hair length and investigation chronology was obtained (Fig. 1). Hair length was about $14 \mathrm{~cm}$ and it was segmented as shown in Fig. 1. 


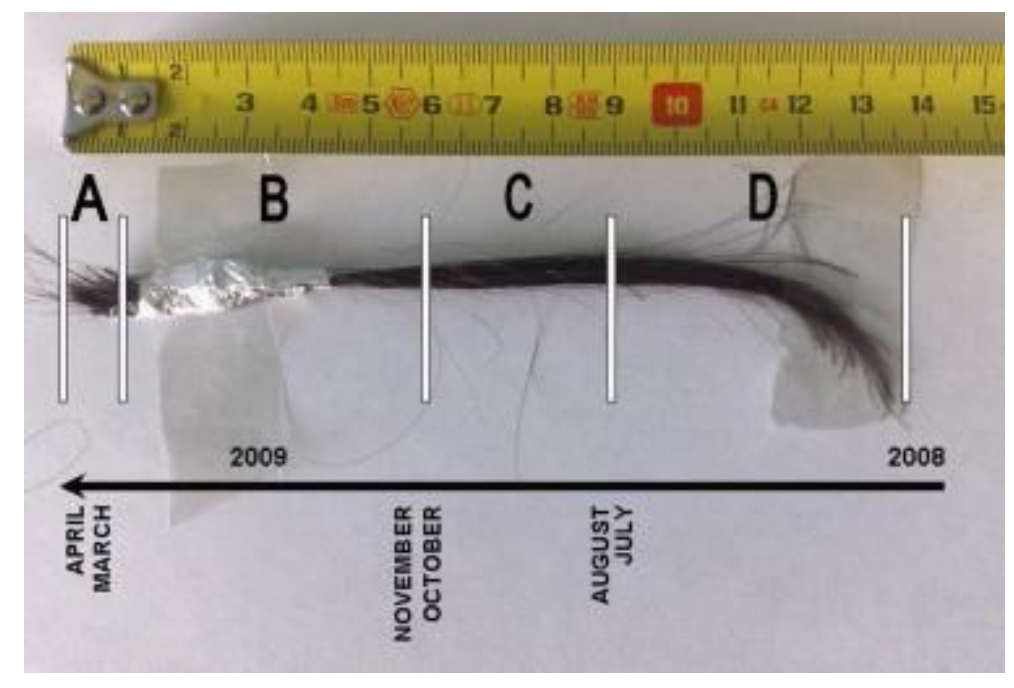

Fig. 1. Relationship between hair length and chronology of investigation.

\subsection{Chemicals and reagents}

Haloperidol and ethaverine were purchased from Sigma-Aldrich (Milan, Italy); methanol, $t$-butyl methyl ether (TBME) were supplied by Riedel-de Haën (Seelze, Germany); sodium hydroxide was obtained from Carlo Erba Reagents (Milan, Italy).

\subsection{Sample preparation}

For systematic search (screening) of toxic substances potentially present, $5 \mathrm{~mL}$ of water from each bottle was basified with 2 drops of $\mathrm{NaOH} 1 \mathrm{~N}$ and ethaverine was added as the internal standard at $3 \mu \mathrm{g} / \mathrm{mL}$ concentration. After extraction with $10 \mathrm{~mL}$ of tert-butylmethylether, the organic layer was dried under nitrogen and the residue was dissolved with $50 \mu \mathrm{L}$ of methanol. Qualitative identification of the organic components present in the bottles was performed using gas chromatography/mass spectrometry (GC-MS) with the mass spectrometer acquiring the spectra in the full scan mode (50-500 amu).

Hair samples were decontaminated by washing with $2 \mathrm{~mL}$ of dichloromethane for $1 \mathrm{~min}$ twice and then were pulverized by a ball mill. Ethaverine at final concentration of $3 \mathrm{ng} / \mathrm{mg}$ was chosen as internal standard. Hair segments, approximately of 30-50 mg, were subjected to basic hydrolysis by adding $5 \mathrm{~mL}$ of $\mathrm{NaOH} \quad 0.1 \mathrm{~N}$ and leaving the process proceed at $75^{\circ} \mathrm{C}$ for $30 \mathrm{~min}$ [6], [7], [8] and [9]. The resulting solution was extracted by $5 \mathrm{~mL}$ of tert-butylmethylether; the organic layer was separated and then dried under nitrogen. The resulting residue was reconstituted with $50 \mu \mathrm{L}$ of methanol and a 1- $\mu \mathrm{L}$ aliquot was injected (split ratio of 10:1) into the GC/MS system operating in the SIM (selected ion monitoring) mode.

\subsection{GC/MS conditions}

GC-MS analyses were performed using a $6890 \mathrm{~N}$ gas chromatograph from Agilent Technologies (Milan, Italy) equipped with a J\&W HP-5 capillary column, $17 \mathrm{~m} \times 0.200 \mathrm{~mm} \times 0.33 \mu \mathrm{m}$. Helium 
was employed as the carrier gas at a constant pressure of 23.24 psi. The gas chromatograph oven temperature was set at $90{ }^{\circ} \mathrm{C}$ for $1 \mathrm{~min}$ and then raised to $180^{\circ} \mathrm{C}$ with a $30^{\circ} \mathrm{C} / \mathrm{min}$ heating rate. The oven temperature was maintained at $180^{\circ} \mathrm{C}$ for $7 \mathrm{~min}$ and then raised to $315^{\circ} \mathrm{C}$ with a $15^{\circ} \mathrm{C} / \mathrm{min}$ heating rate. The total run time was $23 \mathrm{~min}$. The gas chromatograph injector and the transfer line were maintained at $280^{\circ} \mathrm{C}$.

The chromatograph was coupled to a 5975-inert MSD from Agilent Technologies (Milan, Italy) with $\mathrm{El}$ at $70 \mathrm{eV}$. Haloperidol was quantitatively determined in the two bottles and all hair segments by operating the mass spectrometer in the SIM mode acquisition. The fragment ions monitored for haloperidol were $m / z 224$ (target ion), 237 and 206 (qualifiers) [10], [11], [12] and [13], while for the internal standard (ethaverine) the diagnostic ions at $\mathrm{m} / \mathrm{z} 366,394$ and 380 were chosen.

\subsection{Method validation}

A standard calibration curve was prepared by spiking blank hair at 0.5, 1.0, 5.0, 10.0 and $20.0 \mathrm{ng} / \mathrm{mg}$. LOD value for haloperidol was estimated as the analyte concentration whose response provided a $\mathrm{S} / \mathrm{N}$ value equal to 3 , as determined from the least abundant among qualifier ions. Estimated LOD numerical value was extrapolated from $\mathrm{S} / \mathrm{N}$ value of the lowest concentration level (LCL) using the corresponding calibration curve. LOQ was consequently calculated as twice the LOD. Relative extraction recovery was determined by comparing the representative peak area of haloperidol extracted from hair spiked at the final concentration of $5.0 \mathrm{ng} / \mathrm{mg}$ with the peak area of a methanolic standard at the same concentration. Within-batch precision (expressed as percent variation coefficient, CV\%) and accuracy (expressed as bias \%), were assessed by extracting and analyzing a series of 5 hair samples spiked at $5.0 \mathrm{ng} / \mathrm{mg}$.

\section{Results and discussion}

\subsection{Validation results}

The calibration plots showed good linearity in the range $0.5-20 \mathrm{ng} / \mathrm{mg}$ with a correlation coefficient of 0.998 . LOD was estimated at $0.25 \mathrm{ng} / \mathrm{mg}$ and, subsequently, LOQ was fixed at $0.50 \mathrm{ng} / \mathrm{mg}$, which is also corresponding to the LCL. The extraction recovery was $71.3 \%$. From the analysis of five replicates of hair samples spiked at the final concentration of $5.0 \mathrm{ng} / \mathrm{mg}$, the within-batch precision resulted $7.7 \%$ and the accuracy (expressed as percent bias) resulted $-1.1 \%$.

\subsection{Experimental results}

Haloperidol was found in bottle 1 at a concentration of $31.5 \mu \mathrm{g} / \mathrm{mL}$ (total amount: $8.8 \mathrm{mg}$ ) and in bottle 2 at $43.6 \mu \mathrm{g} / \mathrm{mL}$ (total amount: $5.9 \mathrm{mg}$ ).

Full scan analysis also revealed the presence of methylparaben, which is the methyl ester of $p$ hydroxybenzoic acid and is commonly used as preservative in several pharmaceutical solutions. 
The n-propylparaben, also used in some haloperidol preparations, was not found in the water samples.

Quantitative determinations of haloperidol in hair segments are reported in Table 1. Haloperidol was not present in segment D corresponding to a remote period likely preceding August 2008.

Table 1.

Results of segmental hair analysis.

\begin{tabular}{|l|l|l|l|}
\hline Specimen (diagnostic window) & Haloperidol & Length $(\mathrm{cm})$ & Concentration $(\mathrm{ng} / \mathrm{mg})$ \\
\hline $\begin{array}{l}\text { Segment A } \\
\text { (March-April 2009) }\end{array}$ & Positive & 1 & 1.4 \\
\hline $\begin{array}{l}\text { Segment B } \\
\text { (November 2008-March 2009) }\end{array}$ & Positive & 5 & 0.5 \\
\hline $\begin{array}{l}\text { Segment C } \\
\text { (August-October 2008) }\end{array}$ & Positive & 3 & 1.9 \\
\hline $\begin{array}{l}\text { Segment D } \\
\text { (before August 2008) }\end{array}$ & Negative & $4-5$ & $<$ LOD \\
\hline
\end{tabular}

Haloperidol is available in Italy mainly under the name of Serenase, as tablets of 1 and $10 \mathrm{mg}$, oral solution of 2 and $10 \mathrm{mg} / \mathrm{mL}$, and injectable solution of $2 \mathrm{mg} / 2 \mathrm{~mL}$ and $5 \mathrm{mg} / 2 \mathrm{~mL}$. Under the name of Haldol, it is produced as $1 \mathrm{mg}$ and $5 \mathrm{mg}$ tablets, oral solution of 2 and $10 \mathrm{mg} / \mathrm{mL}$ and injectable solution of $5 \mathrm{mg}$.

GC-MS analysis also revealed the presence of methylparaben, used as preservative in all oral solutions and in the $2 \mathrm{mg}$ injectable solution of Serenase.

Methylparaben is an anti-fungal agent commonly used as preservative in cosmetics, food, beverages and pharmaceuticals. It is readily absorbed from the gastrointestinal tract or through the skin [14]. Studies on the acute, subchronic, and chronic effects in rodents indicate that parabens are practically non-toxic[14] and [15]. No analytical evidence of the presence of other preservatives was observed. In particular, the presence of propylparaben, another preservative used in several preparations of Serenase and Haldol, could be excluded. As shown in Table 2, the unique pharmaceutical preparation, among the ones commercialized in Italy, containing methylparaben but not containing propylparaben is the $2 \mathrm{mg} / \mathrm{mL}$ oral solution of Haldol. Therefore, this is the preparation most likely utilized to poison the two bottles of water. 
Table 2.

Comparison of preservatives in different pharmaceutical preparations and in samples analyzed.

\begin{tabular}{|l|l|l|}
\hline Preparation & Methylparaben & Propylparaben \\
\hline Serenase (tablets) & NO & NO \\
\hline Serenase (oral solutions) & YES & YES \\
\hline Serenase $(2 \mathrm{mg} / 2 \mathrm{~mL}$ solution for injection) & YES & YES \\
\hline Serenase $(5 \mathrm{mg} / 2 \mathrm{~mL}$ solution for injection) & NO & NO \\
\hline Haldol (tablets) & NO & NO \\
\hline Haldol $(2 \mathrm{mg} / \mathrm{mL}$ oral solution) & YES & NO \\
\hline Haldol $(10 \mathrm{mg} / \mathrm{mL}$ oral solution) & YES & YES \\
\hline Haldol $(5 \mathrm{mg} / \mathrm{mL}$ solution for injection) & NO & NO \\
\hline Bottle 1 & YES & NO \\
\hline Bottle 2 & YES & NO \\
\hline
\end{tabular}

Segmental hair analysis (Table 1 ) revealed high concentration of haloperidol in segments $A$ (March-April 2009) and C (August-October 2008) and significantly lower concentration in segment B (November 2008-March 2009). Based on these results, the nurse consumed haloperidol approximately in the period from August 2008 to March 2009 (segments A-C). Particularly, high concentrations of haloperidol in hair, found in segments $A$ and $C$, correspond to the periods when the appearance of serious side effects due to haloperidol intoxication were ascertained (segment A: $1.4 \mathrm{ng} / \mathrm{mg}$; segment C: $1.9 \mathrm{ng} / \mathrm{mg}$ ). These levels appear lower than the concentrations previously found on psychiatric patients, which, however, referred to prospective studies with controlled drug administration on few subjects [16] and [17]. In real cases, where the intake of the drug is likely to be occasional and the doses are not predictable, it can be controversial to look for any relationship between the amount of drug detected in the hair and the quantity of the drug itself consumed by the subject.

From the presence of haloperidol and methylparaben in the bottles from which the nurse used to drink her water, and from segmental hair analysis, also showing relevant concentrations of haloperidol, it can be concluded that someone was likely adding Haldol $2 \mathrm{mg} / \mathrm{mL}$ oral solution to these bottles, starting around August 2008, and that the nurse unwittingly consumed this drug by regular drinking from these bottles. The doses consumed were particularly high in the periods when the most severe side-effects were ascertained, requiring hospitalization of the nurse. 


\section{References}

- [1] R.C. Baselt. Disposition of Toxic Drugs and Chemicals in Man. (seventh ed.)Biomedical Publications, Foster City, CA (2004)

$\circ \quad$ [2] D.R.A. Uges, J.M.H. Conemans. M.J. Bogusz (Ed.), Handbook of Analytical Separations, Forensic Science, vol. 2Elsevier, Amsterdam (2000)

- [3] J. Volavka, T. Cooper, P. Czobor, I. Bitter, M. Meisner, E. Laska, P. Gastanaga, M. Krakowski, J.C.Y. Chou, M. Crowner, R. Douyon. Haloperidol blood levels and clinical effects. Arch. Gen. Psychol., 49 (1992), pp. 354-361

$\circ \quad$ [4] J.V.K. Scialli, W.E. Thornton. Toxic reactions from a haloperidol overdose in two children. J. Am. Med. Assoc., 239 (1978), pp. 48-49

$\circ$ [5] V. Pecoraro, I.P.L. Astore. Measurement of hair growth under physiological conditions. C.E. Orphanos, R. Happle (Eds.), Hair and Hair Disease, Springer Verlag, Berlin (1990)

$\circ \quad$ [6] W.A. Baumgartner, V.A. Hill. Sample preparation techniques. Forensic Sci. Int., 63 (1993), pp. $121-135$

$\circ$ [7] P. Kintz. Analytical and Practical Aspects of Drug Testing in Hair. Taylor and Francis, Boca Raton, FL (2007)

$\circ$ [8] M. Shen, P. Xiang, H. Wu, B. Shen, Z. Huang. Detection of antidepressant and antipsychotic drugs in human hair. Forensic Sci. Int., 126 (2002), p. 153

- [9] F.J. Couper, I.M. Mclntyre, O.H. Drummer. Detection of antidepressant and antipsychotic drugs in post-mortem human scalp hair. J. Forensic Sci., 40 (1995), pp. 87-90

- [10] A. Forsman, E. Mårtensson, G. Nyberg, R. Ohman. A gas chromatographic method for determining haloperidol. Arch. Pharm., 286 (1974), pp. 113-124

- [11] M. Franklin. Gas-chromatographic measurement of haloperidol in plasma. Clin. Chem., 26 (1980), pp. 1367-1368

- [12] H. Haring, Z. Salama, L. Todesko, H. Jaeger. Gas chromatographic-mass spectrometric determination of haloperidol in plasma. Arzneimittel Forsch., 37 (1987), pp. 1402-1404

- [13] M.A. Moulin, R. Camsonne, J.P. Davy, E. Poilpre, P. Morel, D. Debruyne, M.C. Bigot. Gas chromatography-electron-impact and chemical-ionization mass spectrometry of haloperidol and its chlorinated homologue. J. Chromatogr., 178 (1979), pp. 324-329 
[14] M.G. Soni, S.L. Taylor, N.A. Greenberg, G.A. Burdock. Evaluation of the health aspects of methyl paraben: a review of the published literature. Food Chem. Toxicol., 40 (2002), pp. 1335-1373

- [15] M.G. Soni, I.G. Carabin, G.A. Burdock. Safety assessment of esters of p-hydroxybenzoic acid (parabens). Food Chem. Toxicol., 43 (2005), pp. 985-1015

- [16] M. Shen, P. Xiang, H. Wu, B. Shen, Z. Huang. Detection of antidepressant and antipsychotic drugs in human hair. Forensic Sci. Int., 126 (2002), pp. 153-161

[ [17] W. Weinmann, C. Müller, S. Vogt, A. Frei. LC-MS-MS analysis of the neuroleptics clozapine, flupentixol, haloperidol, penfluridol, thioridazine, zuclopenthixol in hair obtained from psychiatric patients. J. Anal. Toxicol., 26 (2002), pp. 303-307 